\title{
15
}

\section{Hybridity and Regulatory Authority in Fiji: Vernacular Perspectives on Gender and Security}

\author{
Nicole George
}

\begin{abstract}
A bicameral parliament with a grass skirt, or some other sort of tokenistic nod to 'the local', does not amount to a hybrid polity. Instead, we see hybridity as a more local but scalar mixing of ideas, norms and personnel, with power in full view. ${ }^{1}$
\end{abstract}

\section{Introduction}

In this chapter, I examine the function of hybridised regulatory authority as it is configured in Fiji and focus specifically on the implications this has for the policing of gender in this Pacific island country. The quote that leads this chapter, from a recent article by Roger Mac Ginty and Oliver Richmond, prompted me to reflect on the symbolism of the dress uniforms that are worn by the Fiji Police Force. In particular, I was reminded of a photograph taken by Ali Rae, an accomplished photojournalist who accompanied me on a fieldwork trip to Suva in 2013. This photograph shows the police force band at the launch of a new communal policing campaign in Suva, resplendent in parade uniforms

1 Mac Ginty and Richmond, 'The Fallacy of Constructing Hybrid Political Orders'. 
consisting of a navy dress shirt and dazzling tailored white formal wraparound sulu (Figure 15.1). But contrary to the more conventional even-hemmed cut of this garment, the hem of the police sulu is styled in a way that references more traditional dress - that is, the pandanus or 'grass skirts' of the region.

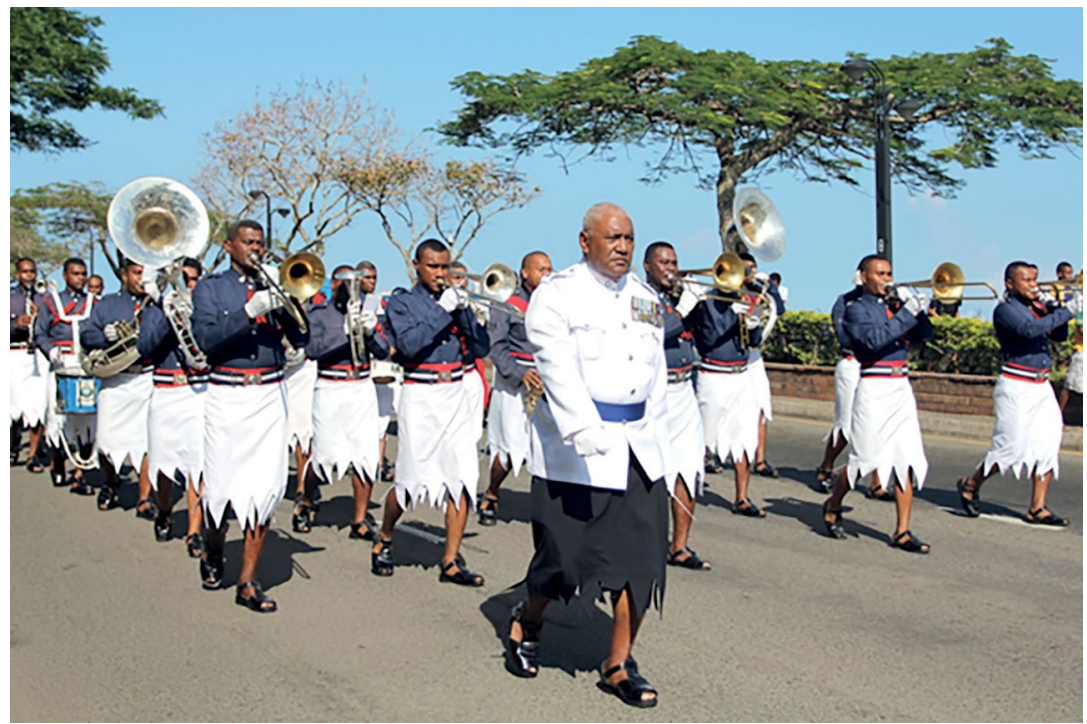

Figure 15.1: The Fiji Police Force band at the launch of a new communal policing campaign, Suva, 2013

Source: Photo by Ali Rae.

As this chapter will demonstrate, this 'nod' to the 'local' should not simply be read only as a tokenistic incorporation of islands 'fashion' in formal police dress. My contention is that this uniform is also more deeply symbolic of the hybridised 'fashioning' of regulatory enforcement in Fiji and the extent to which the everyday operations of the state security agencies in Fiji are shaped by, and intertwined with, powerful institutions of customary and religious authority. At first glance, this scenario may be taken to suggest that state policing authority, fashioned in this way, is brought 'closer to the people', ${ }^{2}$ resonating with the values, practices and protocols that lie at the heart of Fijian identity. ${ }^{3}$ What is less sure is the extent to which this system of authority makes 'everyday emancipatory

2 Baker and Scheye, 'Multi-layered Justice and Security Delivery', 512.

3 Brown et al., 'Challenging Statebuilding as Peacebuilding', 101. 
forms of peace' ${ }^{3}$ more achievable or more accessible to all who live within its jurisdiction. This question comes into sharp relief if we ask about the ways gender and sexuality are policed within this hybridised system of regulatory authority.

This question has critical implications for the study of hybridity and hybrid regulatory authority more generally. The concept of hybridity has been invoked by those aiming to understand where and how localised authority functions in ways that may potentially complement 'top-down' sites of regulatory authority, helping to consolidate order through stronger recognition of 'local strengths and resilience. ${ }^{5}$

But there are more sceptical appraisals of this concept, too. Some have illustrated the co-constitutive nature of the relationship between 'topdown' and 'bottom-up' sites of regulatory authority, and the extent to which formalised sites of authority may construct their own 'local' according to what they are able to 'find, initiate or are willing to support financially'. ${ }^{6}$ Others have given close consideration to the ways cultural practices may be appropriated by particular groups to serve sectional interests in ways that potentially subvert the original aims, symbolism or meaning of that activity; a scenario which, in certain contexts, explains the increasing commercialisation of traditional gift giving as part of customary reconciliation practices, for example. ${ }^{7}$ A further critical contention, pertinent to debate on hybridity and enforcement, is that the recent hybrid turn aligns with a global neoliberal orthodoxy which encourages public sector retreat from security provision and the outsourcing of security agency work to privatised military and security companies with attendant problems of accountability. ${ }^{8}$

It is only recently that the concept of hybridity has been subject to gendered critique, work which has been pioneered by the likes of Annika Björkdahl, ${ }^{9}$ writing with Kristine Höglund ${ }^{10}$ and Johanna Selimovic. ${ }^{11}$ Drawing on Anna Tsing's foundational work in globalisation and

\footnotetext{
4 Mac Ginty and Richmond, 'The Fallacy of Constructing Hybrid Political Orders', 220.

5 Brown et al., 'Challenging Statebuilding as Peacebuilding', 101; Mac Ginty, 'Indigenous Peace-Making'.

6 Heathershaw, 'Towards Better Theories of Peacebuilding', 280.

7 Wallis et al., 'Political Reconciliation in Timor Leste'.

8 Abrahamsen and Williams, Security beyond the State.

9 Björkdahl, 'A Gender-Just Peace?'.

10 Björkdahl and Höglund, 'Precarious Peacebuilding'.

11 Björkdahl and Selimovic, 'Gendering Agency in Transitional Justice'.
} 
friction, ${ }^{12}$ Björkdahl, writing with her various co-authors, has emphasised the 'frictions' that occur when there is an interplay between 'bottom-up' and 'top-down' sites of authority and the extent to which sites of 'local agency' working in cooperation with more formalised sites of authority can be generative of their own gendered exclusions and restrictions. ${ }^{13}$ These studies pose important questions about the forms of social control that are legitimated within hybridised environments and how these may compound rather than alleviate gendered insecurity.

How might this frictional interplay between state and non-state sites of regulatory authority be explained in Fiji and what are the frictional gendered outcomes that are produced in this process? Scholarly enquiry into the indigenisation of state agencies of regulatory authority in Fiji provides an important context for this question. This 'indigenisation' has been explained as a contemporary extension of the paternalistic system of colonial authority, devised by the British in Fiji, which enabled them to manage, and keep distinct, the spaces in which indigenous Fijians and, with the beginning of indenture, the imported population of Indian labourers were able to move. ${ }^{14}$ Through a system of indirect rule, indigenous sites of authority were rearticulated into the formal system of state regulation. This strategy assisted the penetration of colonial authority into indigenous communities, and endowed the standing of Fijian populations with a particular sort of legitimacy in the eyes of the state. At the same time, this system of indigenised authority emphasised the distinctiveness of the Indian population and undermined the legitimacy of Indians' demands for similar sorts of protective recognition within state structures of regulatory authority. ${ }^{15}$

Much has been written on the contemporary legacies of this scenario in Fiji and the implications this has for the operations of state agencies of security and enforcement. ${ }^{16}$ But, beyond the important work done by local gender advocates, very little attention has been focused on the various ways that this fusing of state and indigenous authority structures shapes the policing of gender and sexuality in Fiji in the contemporary context. In this chapter, I squarely address this issue. My contention

12 Tsing, Friction.

13 Björkdahl and Selimovic, 'Gendering Agency in Transitional Justice', 167.

14 Firth, 'Colonial Administration'.

15 Kelly and Kaplan, Represented Communities.

16 Halapua, Tradition, Lotu and Militarism in Fiji; Newland, 'New Methodism and Old'; Trnka, 'Remythologizing the State'. 
is that even when policy reforms advocating a more liberal policing of gender, or race, have been adopted, the particular configuration of regulatory authority that operates in Fiji tends to result in everyday policing practice which punishes expressions of gender or sexuality that do not adhere to heterosexual conjugal norms. However, this defence of what I term 'conjugal order ${ }^{17}$ is undertaken by police, not simply because to do otherwise is understood by Fiji Police Force officers as a violation of cultural or religious values or protocols that lie at the heart of expressions of indigenous identity, but also because it is understood to pose a threat to widely and deeply held notions of community order and security.

I develop these claims more fully in the following sections of this chapter. First, I briefly establish an intellectual context for the arguments I make here, situating this particular enquiry within a broader debate on gender, rights and culture in the Pacific islands. Second, I draw on feminist contributions to debate on the concept of hybridity to develop a conceptual framework for my examination of gender and hybridised authority in Fiji. Third, I examine the way in which security as a concept is locally defined or 'vernacularised' 18 and why this is relevant to the policing of gender in Fiji. In the fourth section of this chapter, I discuss everyday examples of policing practice to substantiate my claims about state security agencies' active defence of conjugal order, showing how this activity is understood to protect the foundations of communal and national order. I conclude with some reflections on the ways that gendered analysis of regulatory authority can contribute to debate on hybridised systems of governance and security into the future.

\section{Gender and hybridity: A context for critique}

Before I progress this discussion further, it is important to establish an intellectual context for the argument I defend here. My effort to uncover the gender-restrictive consequences that accrue when policing is shaped by intertwined sources of customary, religious and state security agency authority in Fiji may be taken by some to suggest that I view the relationship between gender, custom and faith, as this operates more generally in Pacific islands societies, with a feminist scepticism or that I see this relationship as solely disempowering for women.

17 MacKenzie, Female Soldiers in Sierra Leone, 4.

18 Bubandt, 'Vernacular Security'. 
This chapter is not written with the aim of defending this view. It is important to research the relationship between gender, rights and culture in the Pacific islands region with caution, sensitivity and in ways that accommodate nuance and contingency. In this vein, my past research on these questions has examined how women's rights activists in Pacific island countries have advanced demands for increased political participation, or improved responses to high rates of gendered violence, in ways that also draw from local religious and cultural discourses. ${ }^{19}$ These acts of 'translation' have yoked universalistic political formulations which establish women's 'rights' to participation and security with customary protocols and biblical teachings which promote respect for women or women's matrilineal authority in familial or clan contexts. I have shown that for women activists in the Pacific islands, these hybridised political claims have been integral to challenging the idea that resistance to women's disadvantage amounts to an acceptance of foreign or inauthentic values that have little resonance with local ways of thinking. ${ }^{20}$

One particularly powerful articulation of this bridging discourse, as it has been formulated in Fiji, has emphasised the significance of the $i$ tatan in the context of debates on high rates of physical violence perpetrated against women in conjugal and family settings in Fiji. This indigenous customary practice requires new husbands to make a formal vow, on presentation of a tabua or whale's tooth to their wife's family, to care for and protect their daughter. Failure to uphold this vow makes the husband answerable to his in-laws, and has often been severely punished. ${ }^{21}$ This customary practice has been invoked by activists seeking to challenge the idea that assertions of women's right to physical security in intimate conjugal or familial settings is a palagi or foreign practice that has no place in Fijian society. ${ }^{22}$ The $i$ tatau example operates here to remind those who are suspicious of 'rights-based' political claims and equate them with 'heartless globalization and irreligion' ${ }^{23}$ that similar principles about the standing of women are upheld in Fijian cultural practice.

However, while my research has demonstrated the political significance of processes of rights translation, I have also drawn attention to the enabling and constraining aspect of this political activity. This question

19 George, "'Starting with a Prayer"; George, "'Just Like Your Mother?”'.

20 See also Douglas, 'Christian Citizens'; Jolly, 'Woman Ikat Raet Long Human Raet o No?'.

21 Daurewa, 'The Power of Fiji's Women'.

22 Ibid.

23 Douglas, 'Christian Citizens', 21. 
gained prominence for me as a new researcher working in Fiji in the early 2000s. At this time, Fiji was recovering from a civilian-led rebel incursion that ultimately resulted in the dismissal of the elected government of the day. This forceful reassertion of indigenous political authority put a brake on the gradual process of liberal reform that had been underway in the country since 1997 when a new constitution allowed Fiji's first Indian-led government to rise to power. The 2000 civilian coup was an event that quickly resharpened and politicised lines of communal and ethnic difference in the country. ${ }^{24}$ Self-installed Fijian nationalists sat at the head of government and an authoritarian state. They were quick to legitimate their power grab through appeals to faith and custom and equally prompt to voice criticism of, and sometimes direct threats against, those who did not share their convictions. In this climate, women activists certainly reflected on the value of careful translation strategies when talking about women's rights. ${ }^{25}$ But in the same breath, many also voiced misgivings over the necessity of delivering their message in this way. They sometimes expressed this frustration by stating that they felt 'boxed in by culture', or at least by the narrow and highly politicised interpretations of culture that were being promoted by sections of the political elite at the time. ${ }^{26}$

For better or worse, the idea that nationalist invocations of culture or faith can be used to justify gender-restrictive practice (across a range of contexts) has shaped the way I come to the debate on hybridity. It is certainly important to recognise, document and celebrate hybridised forms of rights advocacy as they are developed by women activists in this context as evidence of political creativity and resourcefulness. But, as I will demonstrate, it is equally important to ask about the gendered relations of power that have been configured through interplaying systems of church and customary authority such as we find in Fiji, and to ask if or how this interplay or hybridity shapes the everyday delivery of regulatory authority. It is my contention that these things come together in Fiji in ways that compound the insecurity of particular groups of women in Fiji in significant ways.

24 Robertson and Sutherland, Government by the Gun.

25 George, Situating Women.

26 George, “"Just Like Your Mother?”; George, Situating Women; George, “"Starting with a Prayer”. 


\section{Hybridity and the everyday policing of conjugal order in Fiji}

It might seem odd to observers of Fiji's politics that my study of gender and policing in Fiji is framed in terms that suggest a restrictive and indeed punitive security environment. After the military took power in Fiji in 2006 (a coup which was justified, on the surface at least, as necessary to curbing the excesses of indigenous nationalism), a number of legal reforms were introduced to improve the way police responded to the crimes of gendered violence, for example, or the way it treated homosexual citizens. The development of the 2009 Domestic Violence Decree, which aimed to reclassify a range of offences occurring in the 'family situation' as criminal acts, is one example of this shift. ${ }^{27}$ Another is the Zero Tolerance Violence Free Community campaign, also launched in 2009, which aims to encourage a rejection of gendered forms of violence at the village level. ${ }^{28}$ The 2013 constitution, replicating clauses present in the 1997 Fiji constitution that was overturned by the government in 2009, also protects Fiji's homosexual citizens from discrimination on the basis of their sexuality. This document also builds on a 2010 decree issued by the military government to decriminalise homosexuality, overturning a colonial-era legal statute making homosexuality a criminal offence. When considered together, these developments suggest that Fijis political elite, who were later democratically elected in 2014, have been keen to present their credentials as gender reformers. Nonetheless, government rhetoric on this subject is soundly contradicted by the everyday operation of state security agencies whose policing of gender seems to frequently operate as if this reform agenda does not exist.

To understand where and, more particularly, how this gap between policy and policing practice is present, it is important to examine how understandings of security are vernacularised in Fiji within a 'hybridised' system of regulatory authority and how this gives a particular shape to the policing of gender in Fiji. To develop this aspect of my argument I draw on Nils Bubandt's ethnographic approach to security.

27 Radio New Zealand, 'Decree in Fiji Aimed at Tackling Domestic Violence'.

28 ABC Radio Australia, 'Fiji Women's Minister Defends Domestic Violence Decree'. 
Bubandt's work calls attention to the way longstanding vernacular influences inflect prevailing 'idioms of uncertainty, order and fear' and help to legitimate specific 'forms of social control'. ${ }^{29}$

Bubandt asks how localised factors shape ideas about 'safe community'. ${ }^{30}$ To do this he investigates how perceived threats to insecurity are framed or, in his words, generate an 'ontological uncertainty'. ${ }^{31}$ From his perspective, efforts to come to grips with the 'problem of security' should pay attention to the 'socially constructed anxiety that shapes pertinent kinds of danger, fears and concerns for a particular community at a particular time'. ${ }^{32}$ As he goes on to argue, this opens the way for investigating how different societies have different ways of 'socially producing ... discursively portraying ... symbolically representing ... and politically managing ontological uncertainty'. ${ }^{33}$ Against this backdrop, he suggests the concept of vernacular security as a 'convenient shorthand' to capture the connection that exists between 'the political rhetoric of safety and an ontology of uncertainty' and also how this connection is managed through the 'relationship that exists between the 'state and the community. ${ }^{34}$

Following on from this, if we are to understand the gendered impacts of hybridised security environments in Fiji, or elsewhere, it seems important to first consider how multiple sites of regulatory authority operate in relation to one another to build social order and, second, to consider how threats to security are framed and legitimised in these contexts. Consequently, we might better understand how gendered forms of order and security are framed and managed by sites of regulatory enforcement but also how these framing and management strategies are reflective of the broader ontology of uncertainty that is generated within the hybridised security environment.

So what form does an ontology of insecurity take within Fiji's hybridised security environment and what are its gendered dimensions? To give some texture to this idea I draw on reflections and observations on the links between indigenous nationalism in Fiji and indigenous insecurity from

$\begin{array}{ll}29 & \text { Bubandt, 'Vernacular Security', } 277 . \\ 30 & \text { Ibid., } 290 . \\ 31 & \text { Ibid., } 277 . \\ 32 & \text { Ibid., } 277 . \\ 33 & \text { Ibid., } 277 . \\ 34 & \text { Ibid., } 281 .\end{array}$ 
one of Fijis leading indigenous statesmen: customary leader, former vice president of Fiji and High Court judge, Ratu Joni Madraiwiwi. According to Madraiwiwi, since the late nineteenth century, Fijians have feared that their culture, their land, their way of life, perhaps their very survival as a people, is threatened by 'forces of change'. ${ }^{35}$ These changes included those wrought by colonialism, most starkly the arrival of indentured Indian labourers to work in the colonial economy and whose descendants remain in Fiji and at one time outnumbered indigenous citizens. ${ }^{36}$ Colonisation also brought Wesleyan Methodist missionaries to Fiji's shores. This latter group successfully converted large sections of the indigenous population to its church. Where religious conversion was not achieved voluntarily, the colonial state imposed its faith upon indigenous populations through militarised means. ${ }^{37}$

This early fusing of the state and Methodist church regulatory authority has survived Fiji's transition to independence and continued to influence military and policing activity in Fiji's highly communalised, postcolonial political environment. In this context, faith and custom function in an intertwined way as Janus-faced signifiers of order and disorder for Fiji's indigenous and predominantly Methodist population. Faith and custom sustain a sense of distinctive Fijian unity and identity but, conversely, also stoke an insistent ontological uncertainty, giving rise to fears about Fijians' ultimate survival and the need for vigorous state protection of indigenous custom and the centrality of their church. ${ }^{38}$ Some Methodist church leaders fuel these fears from the pulpit, encouraging their congregations to reflect upon the dangers posed to Fijian unity by urbanism, individualism, consumerism and sometimes even indigenous customs. ${ }^{39}$ For assisting this sense of unease, Fijian Methodism has been described as 'not quite the opium of the masses', but rather 'the caffeine of the masses' which 'energises people while intensifying their anxieties'. ${ }^{40}$

In this sense, to explain the function of hybridised regulatory authority in Fiji, it is important to consider how the exercise of state security and authority is actively shaped and influenced by religious and customary

35 Madraiwiwi, 'On Understanding the Fijian People', 23.

36 Firth, 'Colonial Administration and the Invention of the Native'.

37 Nicole, Disturbing History, 17.

38 Robertson and Sutherland, Government by the Gun, 50-74; Tomlinson, In God's Image, 168.

39 Tomlinson, In God's Image, 168.

40 Ibid., 25. 
institutions. But beyond this, we need to also examine the vernacularised (and gendered) understandings of security and order that circulate and are privileged within this regulatory system.

Feminist security studies provide an important backdrop for this type of enquiry, showing the anti-emancipatory, and indeed gender-restrictive, discourses that emerge when societies are perceived to be under threat. In these contexts, gendered tropes of protection come powerfully to the fore ${ }^{41}$ In the process of holding off these threats, women are frequently identified by community leaders as the bearers of 'distinctive' feminised cultural norms which may be articulated in an idealised, restrictive and subordinating form. ${ }^{42}$ Nonetheless, these norms also establish a foundation for notions of gender security, emphasising dutiful and dependent women as those most worthy of protection. ${ }^{43}$ In these contexts, there may be a vigorous policing of women's identity and behaviour to ensure those gendered norms predominate. The aim here is not simply to regulate (women's) individual behaviour, but to police these norms because they are understood to provide the foundation for a more generalised sense of community order that is perceived to be under threat. ${ }^{44}$

Megan MacKenzie develops the term 'conjugal order' to capture the idea that there is frequently a link to be drawn between the 'laws and social norms that serve to regulate sexuality' and broader notions of order and stability. ${ }^{45}$ Hence she considers how campaigns to protect strongly feminised ideals of domesticity, obedience and conjugal propriety become integral to the broader efforts to maintain forms of order. These broad trends may help to generate ideals of femininity that are upheld in a narrow, 'ethnicised' form ${ }^{46}$ that may deny women's capacity for agency and casts activity that does not conform to the feminine ideal as gendered dissidence.

41 Cohn and Jacobson, 'Women and Political Activism', 114; Enloe, Bananas, Beaches and Bases; Enloe, The Curious Feminist; Young, 'The Logic of Masculinist Protection'.

42 de Alwis et al., 'Women and Peace Processes', 178; Young, 'The Logic of Masculinist Protection', 14.

43 McLeod, 'A Feminist Approach to Hybridity', 54; Young, 'The Logic of Masculinist Protection', 14.

44 Pettman, 'Boundary Politics', 196-197.

45 MacKenzie, Female Soldiers in Sierra Leone, 4.

46 Björkdahl and Selimovic, 'Gendering Agency in Transitional Justice', 167. 
To understand the ways in which gender and hybridised regulatory authority in Fiji intersect it is important to consider the particular kinds of institutional interplay that shape state policing authority and activity in this context. But beyond this, it is also important to consider the discourses that fuel an insistent ontology of uncertainty in this hybridised context, and how these elements come together to legitimate a restrictive policing of conjugal norms because this is understood to be foundational to the achievement of community order, safety and wellbeing.

In this context, the regulatory authority of custom, and Fijian Methodism, has been described as a normative 'mould' shaping the psyche of Fiji's security agencies, ${ }^{47}$ which predominantly comprise Fijian personnel and tend, correspondingly, to assess and police threats to order in ways that reflect an indigenous 'ontology of insecurity'. Narrow norms of conjugal order are upheld by agencies of regulatory authority in this context, not simply because this accords with the dictates of custom or faith, but because these norms are viewed as foundational to the achievement of a broader social order that requires vigilant protection. As I will now demonstrate, this scenario has resulted in practical policing which generates restrictive and sometimes highly punitive outcomes for women and men whose behaviour and expressions of sexuality are deemed to disrupt norms of conjugal order. It is my contention that these trends persist regardless of whether the political elite in power in Fiji advocates strongly nationalist or more reformist political sympathies. The gendered brunt of this hybridised exercise of authority has been particularly felt by Fiji's sex-worker population, gay and lesbian communities, and women seeking protection from gendered forms of violence.

\section{Policing conjugal order: Regulating sexuality}

Scrutiny of policing in the years following the Fijian military coup of 2006 indicates the consistent ways in which gender is policed within the country's hybridised system of regulatory authority. Despite its commitments to ending the indigenous capture of the state, the military government that assumed power at this time appointed a conservative and deeply religious senior military officer to the position of police commissioner in 2007. Under this command, the Fiji Police Force then

47 Teaiwa, 'Articulated Cultures'. 
adopted an evangelistic approach to crime prevention known as the Souls to Jesus campaign which required officers to reflect on their duty to 'be God's Ambassadors' 48 and, through their own example, encourage a 'reconfiguring of public morality' as part of their crime-prevention work. ${ }^{49}$ Officers on patrol were instructed to carry bibles as part of their kit, desk officers were required to answer the phone saying 'Praise the Lord' and the police band was instructed to play only Christian songs of worship. Police officers' morality enforcement saw them preach messages of restraint to couples embracing on Suva's sea wall, or young people frequenting Suva's busy nightclub strips. ${ }^{50}$

Those whose behaviour posed more serious threats to norms of conjugal propriety were subject to more serious forms of regulation. This was particularly so for sex workers who were subject to increasing forms of police surveillance. A new crimes decree enacted by the military government in 2009 gave police broader authority to round up and detain sex workers. But in Fiji, sex work is also discussed in ways which suggest it is a powerful source of ontological insecurity. Debates on the legalisation of sex work, for example, are commonly resisted in ways which pathologise this activity or which suggest that decriminalisation will invite 'divine retribution' upon the country. ${ }^{51}$ Against this backdrop, regulatory interventions legitimised by the 2009 crimes decree saw detained sex workers subjected to brutal and degrading extrajudicial punishments while in police custody. These included detainees being forced to jump from bridges into the dark waters of sea inlets at night, detainees being stripped and having their heads shaved, and some subjected to forced labour inside military and police barracks. ${ }^{52}$

Fiji Police Force officers' treatment of Fiji's gay and lesbian communities was similarly discriminatory and punitive, despite a military decree in 2010 decriminalising homosexuality. Like the issue of sex work, debate on homosexuality and the rights of gay people in Fiji tends to expose how these questions are publicly framed as posing a challenge to the prevailing conjugal order, and, more broadly, fuel ontological insecurity. My previous work on these questions has shown that, despite more moderate religious

\footnotetext{
48 Trnka, 'Remythologizing the State', 81.

49 Ibid., 82.

50 McGeough, 'An Unholy Alliance'.

51 Pratibha, 'Rooting Out Prostitution and Associated Illicit Practices'; Singh, 'Prostitution Law Changes Fiji's Night Life'; Vakaliwaliwa, 'Question of Prostitution'.

52 McMillan and Worth, Sex Workers and HIV Prevention in Fiji.
} 
leadership on this issue, many highly vocal church leaders frame tolerance of homosexuality as a 'cancer' that will invade the country or a 'curse' that will 'swamp' Fiji like a 'tsunami'. ${ }^{33}$ This helps to explain why, despite legal and constitutional provisions outlawing discrimination on the basis of sexuality, state regulatory authorities have a well-established history of discriminating and harassing Fiji's homosexual community. ${ }^{54}$ In 2007 , a new case of this sort brought these broader tendencies into stark and disturbing contrast.

This incident involved the conduct of an auxiliary policeman who was found guilty of raping his sister, an act which he allegedly perpetrated to punish her for her involvement in a same-sex relationship and to rid her of her homosexuality. When this case was later brought to court, the presiding judge found the perpetrator guilty but also exonerated his behaviour in a judgement which stated that his normal reason was impaired by drunkenness. The light sentence, suspended for eight years, required the perpetrator to be jailed only at weekends. ${ }^{55}$ This caused outcry among gender and human rights activists and was eventually overturned in the High Court after a long five-year interval. Nonetheless, this case conforms to a longstanding pattern of punitive and discriminatory responses displayed by regulatory authorities towards sex workers and homosexual citizens in Fiji. ${ }^{56}$ There exists a pattern suggesting that the violence perpetrated against these groups by regulatory authorities is excusable because it is less grave than the embodied threats these citizens are felt to pose, both personally and collectively, to the ordering of a 'safe community'.

\section{Policing conjugal order: Violence against women}

In response to the excessive ways in which policing authority was exercised during the Souls to Jesus campaign, the Fiji Police Force later sought to soften its image through the development of a new community, or Duavata policing program, rolled out across a range of jurisdictions in

53 Pratibha, 'Rooting Out Prostitution'.

54 FWCC, Misogyny and Homophobia in the Fiji Police Force; George, 'Contending Masculinities and the Limits of Tolerance'; George, 'In Sickness and in Health'.

55 Narayan, 'Sister Rapist Serves Sentence Only on Weekends'.

56 George, 'In Sickness and in Health'. 
2010. The term duavata is Fijian and expresses the idea of communities coming together. It is used by the police force to encourage the idea that the police and the community are partners in the effort to 'resolve identified problems in order to prevent crime ${ }^{57}$ Outwardly, this program seemed to traverse Fijis communal identifications and involved the participation of both Indian and Fijian industry, cultural and sporting groups, in a shift from the earlier Souls to Jesus campaign, which was exclusively Christian and evangelistic. Nonetheless, deeper scrutiny suggests that even within this new program, there is a hybridised aspect of state security agency operations that continues to function in gender-restrictive ways.

A central component of the Duavata policing program has been a zerotolerance initiative on violence against women that encourages villages to declare themselves 'violence free' and involves community members as both stakeholders and participants in law and order provision. The program is designed to work in collaboration with state policing, but also aims to build community awareness that gender violence is a crime. Hence community leaders are trained to become designated 'gatekeepers' equipped with skills to reconcile conjugal disputes so that violence in the home or family is de-escalated or avoided altogether. ${ }^{58}$ Should community interventions fail, the 2009 Domestic Violence Decree authorises a tough law and order response towards the perpetrators of gender violence.

But the Fiji Police Force's hardline authoritarianism, operating in tandem with informal sites of authority, also undermines the success of this policing program. On one hand, local stakeholders have been found to encourage reconciliation between aggrieved family members so that the customary and religious integrity of the marriage and the family remains intact. Accordingly, women are often urged to return to violent conjugal or familial environments and deterred from seeking external forms of protection or justice by making complaints known to police officers. On the other hand, an under-reporting of incidents of gender violence to police authorities is also said to have occurred because villages who declare themselves 'violence free' are eager to maintain their positive profile with potentially punitive state authorities and have become fearful of unwanted police scrutiny. ${ }^{59}$

57 FPF, Fiji Police Duavata Community Policing Model.

58 ABC Radio Australia, 'Fiji Women's Minister Defends Domestic Violence Decree'.

59 FWCC, Somebody's Life, Everybody's Business; Tukuwasa, 'Fiji Should Not Bank on Zero Reporting'. 
Government sources have proudly advocated the successes of this program, ${ }^{60}$ but women's non-government organisations in Fiji continue to raise concerns about the efficacy of these initiatives. ${ }^{61}$ Allegations that state police officers are themselves perpetrators of this form of violence also undermines government advocacy of the policy gains on violence against women. ${ }^{62}$ In this context, reforms designed to improve state agencies' responses to cases of violence against women have been undermined because they are layered over a hybridised system of regulatory authority where threats posed to conjugal and familial integrity are treated as a more serious source of ontological uncertainty than the physical insecurity that women might be exposed to within conjugal and familial settings and at the hands of police themselves. The community policing model may be designed to resonate with the 'the grain of local beliefs', ${ }^{63}$ but in practice it has not provided any strong guarantee that women who are exposed to violence in the home and within their families can rely on state protection or intervention to uphold their right to safety.

\section{Conclusion}

Hybridity as a concept may presently be much in vogue in the fields of policing studies and in studies of statebuilding, and drawn upon to explain the problematic consequences of international interventions that attempt to layer institutions of governance in contexts 'without peace ... without reconciliation' ${ }^{64}$ According to Oliver Richmond, these challenges can be reconciled when there is a prior commitment to 'a mutual process ... which negotiates with local customary, cultural, political, social, class, economic and often religious dynamics' in combination with the 'thin cosmopolitan ideas upheld by democracy, human rights, welfare [and] rule of law'. ${ }^{65}$

It is perhaps revealing that Richmond's list of local dynamics does not include a mention of gender. This oversight requires more than a passing acknowledgement. There is a need, in my view, for closer and more nuanced thinking about the vernacularised ontologies of uncertainty

60 ABC Radio Australia, 'Fiji Women's Minister Defends Domestic Violence Decree'.

61 FWCC, Somebody's Life, Everybody's Business.

62 Tahana, 'Fiji PM's Violence Condemnation Rings Hollow for Some'.

63 Dinnen and Peake, 'More than Just Policing', 572.

64 Richmond, 'Between Peacebuilding and Statebuilding', 174.

65 Ibid. 
and insecurity that are generated in hybridised environments, and the potential for restrictive disciplinary outcomes to be legitimated as part of the interplay between state and non-state sites of regulatory authority.

As I have shown, this interplay can 'fashion' (to return to the metaphor invoked at the start of this chapter) the regulatory environment in Fiji so that it delivers strongly gendered forms of policing that do little to address the insecurities of those who are locally understood to pose a threat to norms of conjugal order and the integrity of the political community more generally. More systematic enquiry needs to be undertaken into the interplays that occur between formal and informal sites of regulatory authority and how these shape vernacular definitions of order and security and, ultimately, the conduct of state agencies. The examples discussed in this chapter show that hybridised systems of authority can produce a strong, but not always just, correlation of security ambitions. In practice these may also deliver gender-discriminatory, gender-restrictive and, in some cases, gender-violent forms of policing practice. 
This text is taken from Hybridity on the Ground in Peacebuilding and Development: Critical Conversations, edited by Joanne Wallis, Lia Kent, Miranda Forsyth, Sinclair Dinnen and Srinjoy Bose, published 2018 by ANU Press, The Australian National University, Canberra, Australia.

doi.org/10.22459/HGPD.03.2018.15 